\title{
A Study of Open Access Journals Using Article Processing Charges \\ David J Solomon
}

College of Human Medicine, Michigan State University

USA

dsolomon@msu.edu

\section{Bo-Christer Björk}

HANKEN School of Economics

Helsinki Finland

Bo-Christer.Bjork@Hanken.fi

\section{Abstract}

Article Processing Charges (APCs) are a central mechanism for funding Open Access (OA) scholarly publishing. We studied the APCs charged and article volumes of journals that were listed in the Directory of Open Access Journals as charging APCs. These included 1,370 journals that published 100,697 articles in 2010. The average APC was 906 US Dollars (USD) calculated over journals and 904 US Dollars USD calculated over articles. The price range varied between 8 and 3,900 USD, with the lowest prices charged by journals published in developing countries and the highest by journals with high impact factors from major international publishers. Journals in Biomedicine represent $59 \%$ of the sample and $58 \%$ of the total article volume. They also had the highest APCs of any discipline. Professionally published journals, both for profit and nonprofit had substantially higher APCs than society, university or scholar/researcher published journals. These price estimates are lower than some previous studies of OA publishing and much lower than is generally charged by subscription publishers making individual articles open access in what are termed hybrid journals. 


\section{A Study of Open Access Journals Using Article Processing Charges}

\section{Introduction}

Scholarly Open Access (OA) journals make their content available online to anyone and in doing so help solve the access challenges posed by subscription journals. Since OA journals do not charge for access, they rely on other means of funding publication. Most of the early OA journals were published by academics largely using voluntary labor and small subsidies. A second wave consisted of established society journals with stable subscription income that made the electronic version of the journal openly accessible, either directly or after a delay of typically six months to a year (Laakso et al 2011).

In 2002 two new professional publishers, the Public Library of Science (PLoS) and BioMed Central (BMC), began establishing journals that rely on article processing charges (APC) paid by the authors, their institutions or funders as their main means of funding their journals' operations. The number of such publishers, journals they publish, as well as of the number of articles published in these journals has been growing rapidly. In the last few years a number of leading traditional publishing companies have also started launching OA journals funded by APCs. As of August 2011 there were 1,825 journals listed in the Directory of Open Access Journals (DOAJ) that, at least by self-report, charge APCs. These represent just over $26 \%$ of all DOAJ journals. 
The APC funded OA model fundamentally changes the relationship among authors, publishers and readers transferring the role of funding the publication from subscribers, most often university libraries, to the authors, their funders or employers. The cost of APCs adds a new dimension to the authors' decisions as to where to attempt to publish their manuscripts. It also changes the focus of the publishers' marketing efforts in that their customers in at least a financial sense are now the authors rather than the subscribers. In addition, the academic libraries' traditional role as an intermediary between the readers and the publishers disappears though in some cases they have taken on a new role of managing the payment of APCs for the authors at their universities.

Charging authors has been a common practice for many years in subscription publishing, in particular among society publishers, who have used page charges as an additional source of income to lower their subscription prices. Commercial scholarly publishers on the other hand have rarely used page charges as a source of funding (Tenopir and King 2000).

In the debate about whether OA publishing should become the predominant model for funding scholarly publishing, there seem to be widely held misconceptions about how commonly APCs are used to fund publication and the typical APC level. Two quite commonly held beliefs are:

1. That most open access journals charge APCs. See for instance. (Kayser, 2010) 
2. That the level of the APCs in full OA journals are in the order of $1,000-3,000$ United States Dollars (USD). (Ware \& Mabe, 2009; Bird ,2010).

One reason for this might be that there has been extensive media coverage of the two leading OA publishers, BMC and PLoS, and that the level of their charges has been generalized to $\mathrm{OA}$ publishing. Also there has been a lack of empirical studies providing comprehensive data on the cost and growth of APC funded OA publishing.

The aim of this study was to expand the research on APC funded OA publishing producing empirical data about the use of such charges. Specifically:

- The number of publishers and journals charging APCs as well as the number of articles these journals publish.

- The size and distribution of APCs based on the number of journals and articles.

- The relationship of the APC level to characteristics of the journals and their publishers, such as the scientific discipline, type of publisher, impact and country of the publisher.

\section{Background}


Based on the early success of BMC and PLoS, dozens of start-up companies have moved into this market. Subscription publishers have also launched what are termed hybrid journals in which they offer authors the option of providing open access to their individual article along with what is otherwise is a subscription journal. In an article published in 2003 David Prosser described this mechanism as a means for established subscription publishers to experiment with $\mathrm{OA}$ without taking significant risks (Prosser 2003). Springer started their “Open Choice" program in 2004 and others have followed. The uniform price level of 3,000 USD that Springer charged for all the journals in their program seems to have set the level for other publishers as well. According to a Springer press release "the 3,000 US dollar fee covers the costs of Springer's publishing service - including a parallel printed version of the article in an established journal" (Springer 2005). The uptake of the hybrid model has so far been very low. According to a recent study the overall uptake has been around $2 \%$ for the roughly 2,000 journals from 12 major publishers offering this option (DallmeierTiessen et al 2010).

During the past years there have been several studies trying to estimate the costs per article of publishing scholarly peer reviewed journals, in order to calculate the cost effects of different scenarios of moving towards OA. A study published by the UK Research Information Network (RIN 2008) estimated that the average publishing and distribution cost per article (excluding the "cost" of unpaid reviewers but including publisher surplus) was 2,863 British Pounds (GBP). The figure is based on an estimate of global revenues for peer review journal publishing and of the number of articles published globally per year (1.59 
million). The researchers estimated that the cost effects of a transition to electronic only publication would reduce the overall cost for publishing, dissemination and local library access provision by $13 \%$ and that a transition to open access publishing financed with author-side payments by a further $7 \%$. A study by Houghton et al (2009) estimated an average publisher cost of around 3,247 (GBP) per article for dual-mode print and electronic publishing, 2,337 (GBP) per article for e-only publishing and 1,524 (GBP) for open access publishing. At the time of writing of these two reports in 2007-2008 one British Pound was worth roughly 2 USD.

In our view the main flaw of almost all previous estimates is that they have been calculated based on the average reported costs or income of traditional subscription publishing. The cost estimates of both electronic only and open access publishing have been derived from these base figures by subtracting the printing and delivery costs for paper versions. The problem with this method is that it doesn't take into account the dynamics of the marketplace and competition in lowering prices. Cost data have in the past stemmed from a number of leading publishers who in an oligopolistic market have been able to set the prices without much pressure to cut costs and streamline processes. An article in the Economist (2011) recently reported that Elsevier, the largest publisher of scholarly journals with almost 2,000 titles, made an operating-profit margin of $36 \%$. Publishers have frequently tried to justify high subscription prices by the need to invest in information technology infrastructure. Many smaller OA publishers have instead used open source publishing solutions as one 
way to cut costs and outsourcing operations like copy-editing and typesetting to countries where labor costs are low.

Since APC funded OA publishing has matured we feel it is possible to estimate the costs of this type of publishing directly by obtaining data from a large representative sample of $\mathrm{OA}$ journals that charge APCs. In this model the costs are estimated based on the revenues from APCs. Getting the basic data (level of charge, number of chargeable articles) is relatively straightforward compared with obtaining data from subscription journal publishers where much of the revenue is obtained from bundled licenses.

So far the most comprehensive empirical study in which the use of APCs in Open Access publishing has been investigated was carried out in the European Commission funded Study of Open Access Publishing (SOAP) project (DallmeierTiessen et al 2010). In the study the focus was on gathering data concerning the 2,823 active English language journals included in the DOAJ in July 2009. The report contains a lot of useful data about the distribution of journals according to size, the size and type of publishers etc. Of interest for this study are the data concerning income sources for 1,958 journals including all major OA publishers. Unfortunately the data is very inconclusive since no actual income sizes or APC sizes were reported. What is reported is which percentage of journals used each of seven funding methods (APCs, membership fees, advertisement, sponsorship, subscription, hard copy, other). Not unsurprisingly $80 \%$ of the journals from large publishers used APCs versus $20 \%$ of the other journals. 
Walters and Linvill (2011) examined 663 journals selected from the DOAJ in six fields of which 29\% charged APCs. They noted while 29\% of the journals charged APCs, they accounted for approximately $50 \%$ of the articles. For journals charging fees, they found the average fee was $\$ 1,109$ with a median of $\$ 1,300$. In many ways our study parallels theirs however we focus exclusively on journals charging APCs while selecting a broader group of disciplines. They in turn included all OA journals in the DOAJ within the 6 fields meeting some basic requirements and were able to compare APC funded journals with those funded by other sources.

In the SOAP project the behavior and attitudes of scientists concerning Open Access publishing were also studied (Dallmeier-Tiessen et al 2011). Questionnaires were sent out to authors who had published with any of the publishers involved in the project. Almost 23,000 authors who had published an article in an OA journal where asked about how much they had paid. Half of the authors had not paid any fee at all, and only $10 \%$ had paid fees exceeding 1,000 Euros. Only $12 \%$ of authors had had to pay themselves whereas $59 \%$ could use funding from research grants and $24 \%$ funding from the employing institution. There were clear differences in the levels paid depending on scientific discipline and country affiliation.

In a recent study we surveyed authors who had published articles in OA journal using APCs (Solomon \& Björk, 2011). The results indicated that research grants and institutional funding are the dominant modes of financing higher level APCs (above 1,000 USD) whereas personal funds where quite common for journals 
lower charges. There were quite distinct differences in behavior and attitudes between scientific disciplines and high income/low income countries. We also found indications that the level of the APC charged was strongly related to the scientific disciplines as well as the ISI impact factors of the journals in question.

\section{Methodology}

Sample - We used metadata retrieved from the DOAJ on 23-Aug-2011 to identify Open Access journals that charge APCs. Along with other self-report data from publishers, the DOAJ has recently included a field specifying whether a journal charges APCs. We identified 1,825 journals in the DOAJ where the publisher indicated the journal charged such fees. These journals served as a basis for our data collection.

We organized the journals by the 512 publishers included in the sample according to the number of journals per publisher. The vast majority (422) were single journal publishers. All journals from publishers with at least 2 journals were included in the sample. The work in extracting data from 422 single journal publishers, each with a uniquely organized web site would have been prohibitive. To represent these publishers we identified 50 randomly selected journals from the single journal publishers. As an afterthought we decided to include all 41 single journal publishers that published at least 100 articles in 2010 based Thompson Reuters Journal Citation Reports (JCR) 2010. This included 8 of the journals we had originally selected in the sampled single 
journal publishers. To avoid fractional journals in the results from the statistical analysis, we weighted the 42 journals we sampled from the remaining 381 remaining single journal publishers by a factor of 9 to maintain their representation among journals listed in the DOAJ that charged APCs. Unless otherwise noted, all of the results presented below are based on the weighted data.

Data Collection - One of the two authors reviewed the web site of each sampled journal or their publisher obtaining the necessary information to determine if the journal actually charged an APC as well as the amount or method in which it was calculated. We also determined how many articles the journals published in 2010. This was determined in a variety of ways. Some publishers listed the number of articles in the volume or used a sequential numbering system for articles within a volume simplifying the process of counting. For some of the journals we obtained approximate 2010 article counts from SCOPUS through the SCImago web site and/or from JCR 2010. When both were available we used the JCR 2010 data. Typically most of the journals with volumes of more than 100 were obtained from one of these indexes to keep the workload manageable. For many of the journals we simply counted the articles on their web site that had been published.

Journals that did not publish articles in 2010 or did not charge APCs were excluded from the sample. It should be noted that the article counts used in this study are for calendar year 2010 however the APCs were those listed at the time of data collection which ranged between the end of September 2011 and mid 
November 2011. In most cases it would have been impossible to determine from the websites what the level of the APC was specifically in 2010.

Publishers used a variety of strategies for determining the APC authors were charged. A detailed description of these strategies and their prominence among publishers is presented elsewhere (Björk \& Solomon, In press). Briefly, some publishers charged a fixed amount for all their journals or charged a fixed amount specific to each journal. Publishers often had different charges for different types of articles (ie research articles, review articles, shorter commentaries). Some publishers charged by the page or a flat fee plus a page charge over a certain amount of pages. Many publishers provide waivers for authors unable to afford to pay but publishers had a variety of criteria for determining eligibility. Some provide discounts for society membership, country of the author(s), and/or discounts for employer membership with the publisher. A few gave discounts for personal memberships or multiple manuscripts submitted in the same year.

In the case of journals using page charges or other differential pricing mechanisms, the authors reviewed a sample of about 10 articles from each journal and devised an estimate that represented the average APC for that journal. Given the variety of strategies for charging APCs, no specific algorithm was used and the calculation was done on a case-by-case basis. In order to check the reliability of the results both authors coded the same set of 10 journals. There were no discrepancies in the article counts. There was a slight 
discrepancy in one of the APCs recorded, 150 USD versus 130 USD. Otherwise our coding of the APCs was consistent.

A total of 13 different currencies were used by the publishers. The majority of APC prices were in US Dollars (USD). Where a publisher posted prices in multiple currencies the USD price was used. APCs in other currencies were converted into USD using the published exchange rate on 23-Nov-2011 obtained from FXware (http://www.fxware.com/en/) .

The DOAJ metadata included information on a number of key journal characteristics. Along with the name of the publisher, the country of the publisher, up to three subject codes for the scientific discipline, the language(s) the journal was published in and the ISSN were included in the data set. Based on the ISSN numbers we merged in article counts and two-year impact factors for 2010 from SCOPUS and the Journal Citation Reports (JCR) 2010. In reviewing the web sites the authors also coded the type of publisher such as commercial society or non-profit, and the journal management software used. In addition, we recorded details about how the APC was calculated. Beyond the categorization on these attributes, notes were also collected on unusual or notable aspects of each publisher.

Calculations of Averages and Medians - Average and median APCs were calculated in two ways. First, based on journals such the average or median reflected the APC charged by the journals included in the study. Secondly these statistics were based on the articles published in 2010 such that they reflected the average or median APC paid 
by authors in 2010 . Each method reflects a somewhat different perspective and since many of the journals published very few articles while others published thousands of articles, these two methods in some cases generated substantially different results. In our view both perspectives are important and depending on the question asked one is generally more appropriate than the other.

\section{Results}

After excluding journals that did not charge APCs or did not publish in 2010, our sample included 1,090 journals of which 64 were single journal publishers. The publishers, number of journals and article counts are given in the Appendix. After weighting the results for the single journal publishers there were an estimated 1,370 journals which published a total of 100,697 articles in 2010 at a cost of 91,078,558 USD. All other statistical results presented below reflect weighting the sample of single journal publishers. Summary statistics on APCs for both the journals as well as the articles published in 2010 are presented in Table 1.

\section{[Figure 1 about here]}

Figure $1 \mathrm{~A}$ and $\mathrm{B}$ present a breakdown of the APC charged into 200 USD categories. Figure 1A presents the breakdown of APCs charged for articles published in 2010. Figure 1B presents the breakdown of APCs charged by journal.

[Figures 1A \& 1B about here]

Figure 2 presents the average APC based on articles published in 2010 broken down by type and size of the publisher. This breakdown is presented in tabular 
form for means and medians for journals and articles published in 2010 in the Appendix.

\section{[Figure 2 about here]}

Figure 3 presents the total expenditure for APCs by discipline category. The actual expenditures are shown above each bar. As can be seen the vast bulk of the expenditures for APC funded open access publishing has been in biomedicine.

\section{[Figure 3 about here]}

Figure 4 presents the average level of the APC by discipline. The means represented by dark bars are based on journals. The lighter bars are based on the number of articles published in 2010. The numbers of journals and articles published in 2010 are listed at the top of each bar.

\section{[Figure 4 about here]}

Figures 5 presents the average APC for the journals grouped into five categories based on the journals' impact factor. The first group includes journals that are not indexed in either Scopus or the ISI web of Science. The impact factor data was for Scopus obtained from the SCImago Journal \& Country Rank portal (www.scimagojr.com/) and for ISI from the Journal Citation reports 2010 (JCR). In both cases two year impact scores were used. Journals in Scopus but not in the JCR were split into a low and high impact group based on the median of the journals in the whole Scopus database. Those journals in the JCR 2010 were split into low and high impact groups based on the median impact of all journals in a combination of the Science and Social Science JRC 2010 Reports. Although 
roughly half the journals were not indexed at all, the proportion of articles in indexed journals was much higher (67\% in ISI) due to the larger article volumes of these journals.

\section{[Figure 5 about here]}

\section{Discussion}

We feel our methodology is robust with a complete sample of all but the smallest OA publishers in the DOAJ where the publishers reported charging APCs and an approximately $11 \%$ random sample of these smaller publishers weighted to represent the full sample of such publishers. Given the ease and lack of any cost of including one's journals in the DOAJ and the visibility it provides, we expect the directory includes virtually all OA publishers that charge APCs though we cannot verify this point. We also cannot estimate the percentage of waivers or discounts granted to authors but we expect waivers have been granted for only a small percentage of the articles published in OA journals that charge fees. We found a small number of publishers who indicated their journals charged fees but we were unable to locate any indication of a fee in the instructions for authors or other documentation on the journal web site. We expect likewise there may have been publishers who did not indicate their journals charged fees but in fact do. We expect that any such biases in our results would be small. 
As can be seen in Figure 1A, journals charging 200 USD or less published by far the most articles. There is also a smaller spike in articles published in the 1,500 - 2,000 USD range, likely reflecting articles from large biomedical publishers such as BioMed Central. There is a smaller spike in the 1,200 - 1,400 USD range possibly reflecting PLoS One which published over 6,700 articles at 1,350 USD in 2010.

The distribution of APCs charged by journals presented in Figure 2B, demonstrates a large number of low to moderate cost journals from below 200 USD up through 800 USD. The large number of journals in the 601 - 800 USD range largely reflects the 200 plus journals published by Bentham Open, all at 800 USD. There is also a large group of journals charging between $\$ 1,601$ and 2,000 USD. These likely reflect BioMed Central and other large biomedical publishers. As with articles, there is a long positively skewed tail of high cost publishers between 2,000 and 4,000 USD.

The average APC of 904 USD for articles published in 2010 and 906 USD for journals as shown in Table 1 is substantially lower than some earlier reported ranges for APCs (Bird 2010, Ware and Mabe 2009). At the same time our finding that approximately $25 \%$ articles published were in journals charging less than 200 USD reflected in Figure 1A are in line with the two recent studies surveying authors who had paid APCs (Dallmeier-Tiessen et al 2011), [Solomon \& Björk 2011]. Walters and Linvill (2011) in a study in carried out in the spring of 2009 
of 663 OA journals in six disciplines found an average APC of 923 USD per journal and 1,109 per article for the 192 journals that charged authors.

Our results are also similar to earlier studies of subscription journals where there are marked differences in pricing level between commercial and society journals (European Commission 2006). As can be seen in Figure 2, in general we found a clear relationship between the magnitude of the APC and the type of publisher. Commercial publishers, which dominate the multi-journal publisher categories, have a higher average APC level. This is particularly evident for commercial publishers with 10 journals or more where the average APC was 1,345 USD for articles published (Breakdown of articles published in 2010 in the Appendix). Scientific societies and universities in general have a much lower pricing level on average 461 USD based on articles published. These publishers tend to be spread throughout the world and appear in many cases to be catering to local authors. The lowest overall averages are found for journals published by universities or university departments (246 USD by articles). This is not surprising in that they may be subsidized by the university either financially or by "in kind" services. The categories of professional non-profit publishers, university presses and journals published by individual scholars are so dominated by a few journals with high quality standards (i.e. PLoS and Oxford University Press) that it is hard to tell whether these results will generalize.

The vast majority of the expenditures for APC funding OA publications are in Biomedicine as shown in Figure 3. This probably reflects a variety of factors. 
The availability of grant funding coupled with funder mandates has certainly had an impact. APC funded publication also began in biomedicine with the creation of BioMed Central and PLoS. Other publishers with relatively high priced APCs such as Frontiers Research Foundation have also contributed to the high expenditures in the biomedical fields. Consistent with Figure 3, Figure 4 shows APCs are much higher in biomedicine than in other disciplines. This can to a large extent be explained by the same factors, relatively high APCs and the availability of grant funding.

Figure 4, also highlights the fact that OA publishing funded through processing fees is today largely concentrated in scientific, technical and medical (STM) fields. There appears, however, to be a growing number of APC funded journals in the social sciences but they are still quite rare in the arts and humanities. This probably reflects both the limited availability of funding and the tendency in these disciplines to emphasize monographs over journal articles for disseminating their work.

According to the fundamentals of microeconomic theory, the market price of a commodity or service is a function of both the supply and the demand. In subscription publishing, the demand side has appeared to dominate and the cost of what are often called "core journals" have increase well beyond the inflation rate perceived by many to be due to the need for librarians to maintain their subscriptions to these journals at any cost. (Panitch \& Michalak, 2005) 
Open Access publishing, with a focus on the individual authors as customers radically changes the dynamics of the market. Authors usually have a choice between a few alternative journals to submit their manuscripts. Most of these alternatives are subscription based, in which publishing in most cases is free of charge to the author. Some might be open access and may require an APC. The authors are faced with the task of choosing a journal which to submit their manuscript taking into account a number of factors (Björk \& Öörni 2009, Solomon \& Björk). These include:

- The fit of the article topic with the journal's scope

- The prestige of the journal (for instance it's impact factor)

- The likelihood of acceptance

- The expected time from submission to publication (if accepted)

- Possible mandate of the research funder that the results must be made openly available

- Whether the journal is Open Access or not

- The level of the APC if the journal charges one

In essence, if an author chooses to submit to a journal that charges an APC, the expected value of the dissemination, branding and other services provided by a journal must exceed the other, potentially no-cost, publishing options. In addition the author must have the financing to fund the APC, either via grants, their employer or by using their own money. Hence we believe the APCs that OA publishers have set for their journals to a large extent reflect what they expect the market can bear, given the "customer value" that they provide to their 
authors. In the long run the charges must of course also be set at a level that provides enough revenue to make the publishing sustainable.

To take a concrete example, the OA publisher Bentham Open has launched over 200 journals in a very short time charging a uniform fee of 800 USD for research articles. After 3-4 years in operation the average number of articles published in these journals is 9 with many journals appearing to be more or less empty placeholders in a uniform publishing IT-platform. This would suggest that authors are not satisfied with the value offering compared to the price.

In contrast to Bentham Open has been the rapid success of PLoS ONE which is likely to publish around 14,000 articles in 2011, for a fixed price of 1,350 USD per article. This is a case of a highly reputed OA publisher offering a novel kind of peer review and rapid publication coupled with a reasonably good impact factor and a technically very advanced e-platform.

Figure 5 provides an interesting and somewhat perplexing view at the relationship between impact factors, perceived by some to be a measure of quality and pricing. The fact that the higher impact factor journals in JCR had by far the highest APC level (1,553 USD for journals) comes as no surprise. Such journals in order to achieve the higher quality often have a lower acceptance rate and salaried editorial staff and hence have more cost per published article. Secondly these journals are predominantly in biomedicine which overall has a higher pricing level. Thirdly authors are probably more willing to pay the higher 
APCs given higher visibility and recognition they get from publishing in journals with above average impact scores.

The average APC level goes in descending order from high impact in the JCR, high impact in SCOPUS, low impact in SCOPUS and non-indexed journals. This is what we expected. What is surprising is that the lower impact journals in the JCR had lower prices than the journals that are not in either index. Thompson Reuters indexes a limited number of journals in the JCR and while their criteria are not made public, the general perception is that only fairly high quality journals are indexed in the JCR. Scopus indexes a larger number of journals but again the perception is that journals are screened for quality before being included in the index. The reason for the lower impact journals in the JCR in general charging a very low APC we believe can be found in the distribution of the journals across types of publishers, country of publication and discipline. The lower impact JCR group contains a large number of society published journals from countries outside the US, UK and Western Europe, who typically have a very moderate pricing level. At the same time there are many new mid or high priced commercial journals in the non-indexed group of journals.

Our data suggest that it might be meaningful to cluster the APC journals in a number of groups:

- A few very high impact journals from well-respected publishers charging 2,000-4,000 USD. 
- A large number of journals in biomedicine from commercial publishers in the range 1,500-2,000 USD, some indexed and some not.

- A quickly growing segment of "megajournals" with prices in the range 1,000-1,500 USD, usually with very broad scopes. These journals have quick submission to publication times and only screen for scientific reliability, leaving it the readers rather than the reviewers to judge the relevance.

- Journals from commercial publishers covering a wide range of disciplines in a mid-price range of 500-1,000

- Lower priced society journals, typical level below 500 USD

- Very low priced journals, below 200 USD, published by both commercial and society publishers in developing countries and mainly catering to authors from the countries in question.

All in all, the scientific publishing landscape is rapidly changing. Our data shows that there were already over 100,000 articles published in APC-financed Open Access journals in 2010 and the number is rapidly increasing. The leading journals have already had time to establish themselves and a sustainable price level. It is interesting to note that a little over 100,000 articles could be published and made available to the global scientific community at an estimated cost of 91 million USD. This can be contrasted to the revenue estimate of 8 billion USD for STM journal publishing constituting the bulk of an estimated 1.5 million overall article volume (Ware and Mabe 2009). 


\section{References}

Beall, J. (2010) “Predatory” Open Access Publishers, The Charleston Advisor, 15.2.2010, eprints.rclis.org/bitstream/10760/14576/1/predatory.pdf

Bird, C. (2010) Continued Adventures in Open Access: 2009 perspective. Learned Publishing; 23(2), 107-116 doi:10.1087/20100205

Björk B-C, Welling P, Laakso M, Majlender P, Hedlund T, Guðnason G. (2010)

Open access to the Scientific Journal Literature: Situation 2009. PLoS ONE 5(6) pp. e11273. doi:10.1371/journal.pone.0011273

Björk, B-C., and Öörni, A., (2009) A Method for Comparing Scholarly Journals as Service Providers to Authors, Serials Review 35(2), June 2009, 62-69.

Björk B-C, Solomon DJ. Pricing principles used by scholarly open access publishers. Learned Publishing. In Press.

Dallmeier-Tiessen, S., Goerner, B., Darby, R., Hyppoelae, J., Igo-Kemenes, P., Kahn, D., Lambert, S., Lengenfelder, A., Leonard, C.,Mele, S., Polydoratou, P., Ross, D.; Ruiz-Perez, S., Schimmer, R., Swaisland, M., and van der Stelt, W., 2010. Open Access Publishing - Models and Attributes, SOAP project report, Max Planck Society digital library e-doc server. Available online:

Http://edoc.mpg.de/478647 
Dallmeier-Tiessen, S., Darby, R., Goerner, B., Hyppoelae, J., Igo-Kemenes, P., Kahn, D., Lambert, S., Lengenfelder, A., Leonard, C., Mele, S., Nowicka, M., Polydoratou, P.,Ross, D., Ruiz-Perez, S., Schimmer, R., Swaisland, M. and van der Stelt, W. (2011) "The SOAP Symposium - III Open Access Publishing Today: What scientists do and why", Powerpoint presentation, SOAP Symposium, January 13th, 2011, Berlin, http://edoc.mpg.de/524967.

DOAJ (2011). Directory of Open Access Journals. Home page. http://www.doaj.org/

Davis, P. (2009-Jun-10) Open Access Publisher Accepts Nonsense Manuscript for Dollars. Posted to The Scholarly Kitchen. http://scholarlykitchen.sspnet.org/2009/06/10/nonsense-for-dollars/

Economist 2011. Academic publishing - Of goats and headaches, One of the best media businesses is also one of the most resented, The Economist, $26^{\text {th }}$ of May 2011, http://www.economist.com/node/18744177

European Commission (2006) Study on the Economic and Technical Evolution of the Scientific Publication Markets in Europe. Brussels: European Commission. Directorate General for Research, http://ec.europa.eu/research/science-soc iety/pdf/scientific-publication-study_en.pdf. 
Houghton, J., Rasmussen, B., Sheehan, P., Oppenheim, C., Morris, A., Creaser, C., Greenwood, H., Summers, M. and Gourlay, A. , (2010) Economic implications of alternative scholarly publishing models: Exploring the costs and benefits. Project Report. Available online: http://ie-repository.jisc.ac.uk/278/.

Kaiser, J. (2010) Free Journals Grow Amid Ongoing Debate Science 20 August 2010: 896-898.DOI:10.1126/science.329.5994.896

Laakso M, Welling P, Bukvova H, Nyman L, Björk B-C, et al. (2011) The Development of Open Access Journal Publishing from 1993 to 2009. PLoS ONE 6(6): e20961. doi:10.1371/journal.pone.0020961

Prosser, David C. From Here to There: A Proposed Mechanism for Transforming Journals from Closed to Open Access. Learned Publishing (2003) 16(3), 1 July $2003,163-166$

RIN, 2008. "Activities, costs and funding flows in the scholarly communications system in the UK," Report, Research Information Network, Available online: http://www.rin.ac.uk/our-work/communicating-anddisseminating-research/activities-costs-and-funding-flows-scholarly-commu).

Panitch JM, Michalak S. The Serials Crisis: A White Paper for the UNC-Chapel Hill Scholarly Communications Convocation.

Http://www.unc.edu/scholcomdig/whitepapers/panitch-michalak.html accessed 2011-Dec-12. 
Solomon DJ, Björk B-C. Publication Fees in open access publishing: Sources of funding and factors influencing choice of journal. Journal of the American Society for Information Science and Technology. (2012) 63(1) 98-107. DOI: 10.1002/asi.21660.

Springer (2005) Springer strengthens its commitment to freely accessible research literature, press release, 16 August 2005, http://www.springer.com/about+springer/media/pressreleases?SGWID=0$11002-2-803740-0$

Tenopir, C. and King, D. (2000) Towards Electronic Journals - Realities for Scientists, Librarians and Publishers, Washington D. C.: Special Libraries Association.

Walters H, Linvill, A (2011) Characteristics of Open Access Journals in six subject areas, College \& Research Libraries, 72(4), pp 372-392

Ware M, Mabe M. (2009) The STM report: An overview of scientific and scholarly journal publishing, International Association of Scientific, Technical and Medical Publishers, 2009. http://www.stmassoc.org/2009 1013 MWC STM Report.pdf 
Table 1

Article Processing Fee (APC) in USD

Summary Statistics by Journals and Articles Published in 2010

$\begin{array}{lcc} & \text { By Journal } & \begin{array}{c}\text { By Article } \\ \text { Published in 2010 }\end{array} \\ \text { Mean } & 906 & 904 \\ \text { Median } & 800 & 740 \\ \text { S.D. } & 642 & 742 \\ \text { Minimum } & 8 & 8 \\ \text { Maximum } & 3,900 & 3,900 \\ \text { Number } & 1,370 & 100,697\end{array}$




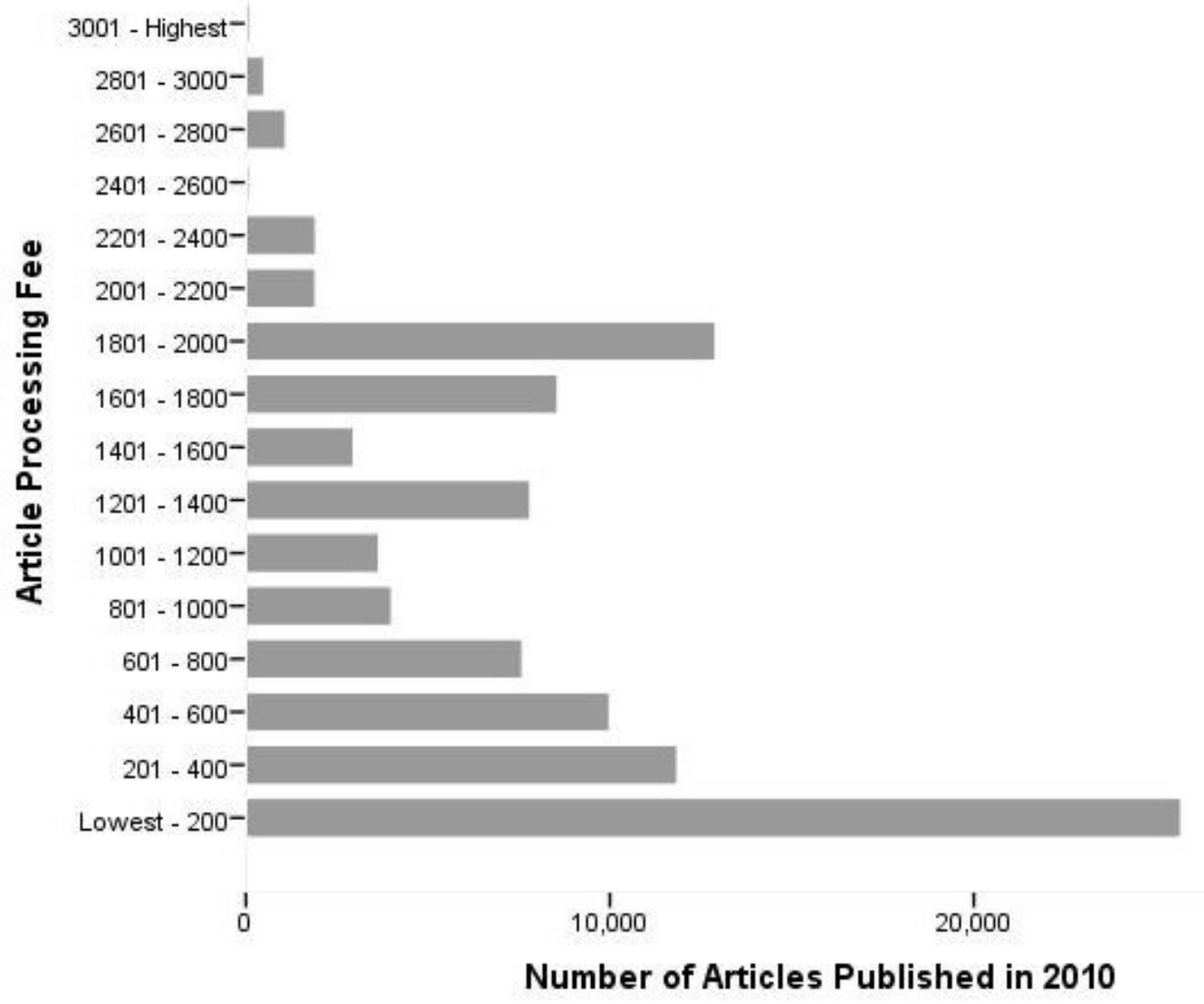

Figure 1A: Number of Articles Published in 2010 by Article Processing Charge Size Category 


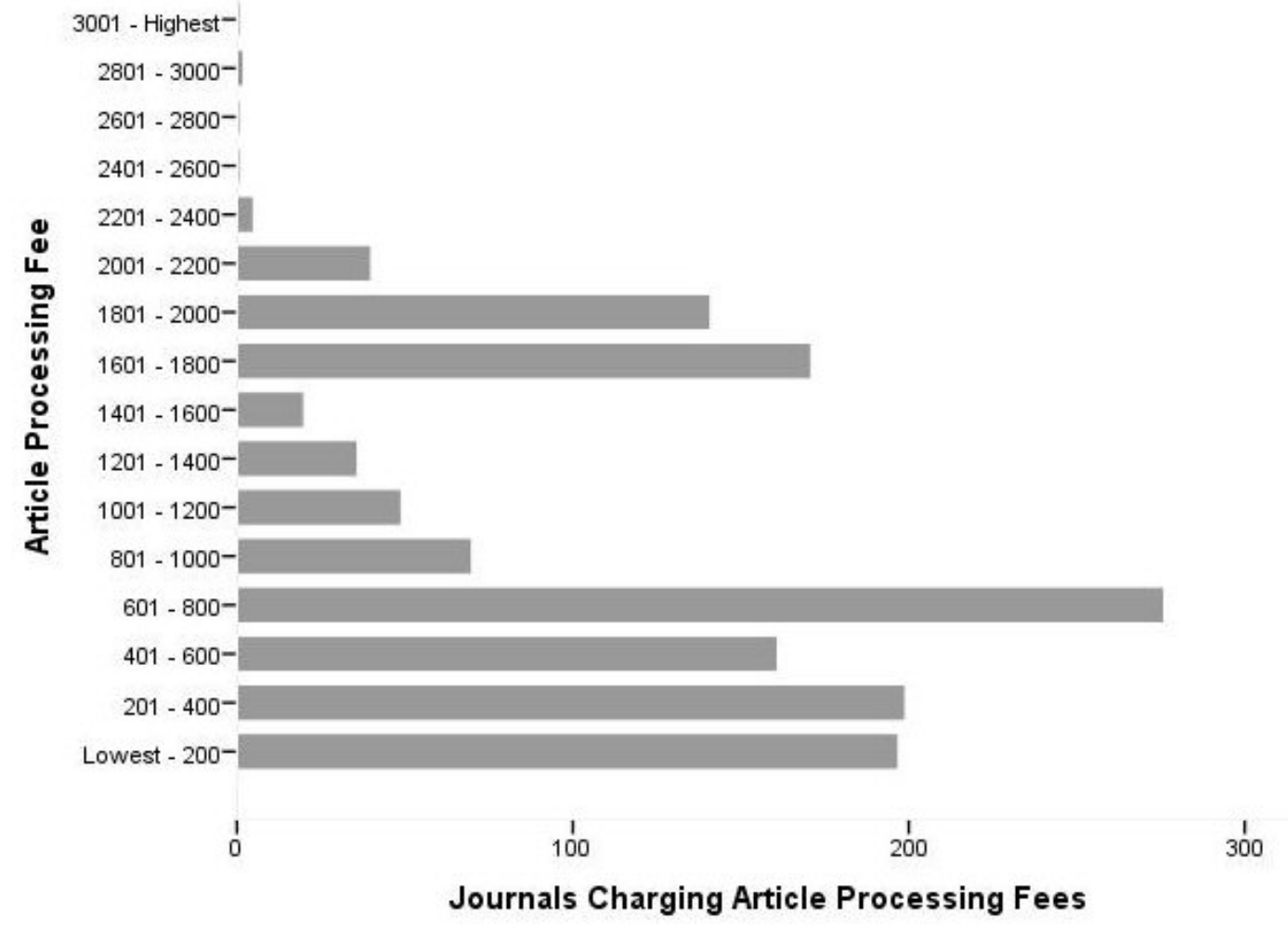

Figure 1B: Number of Journals by Article Processing Charge Size Category 


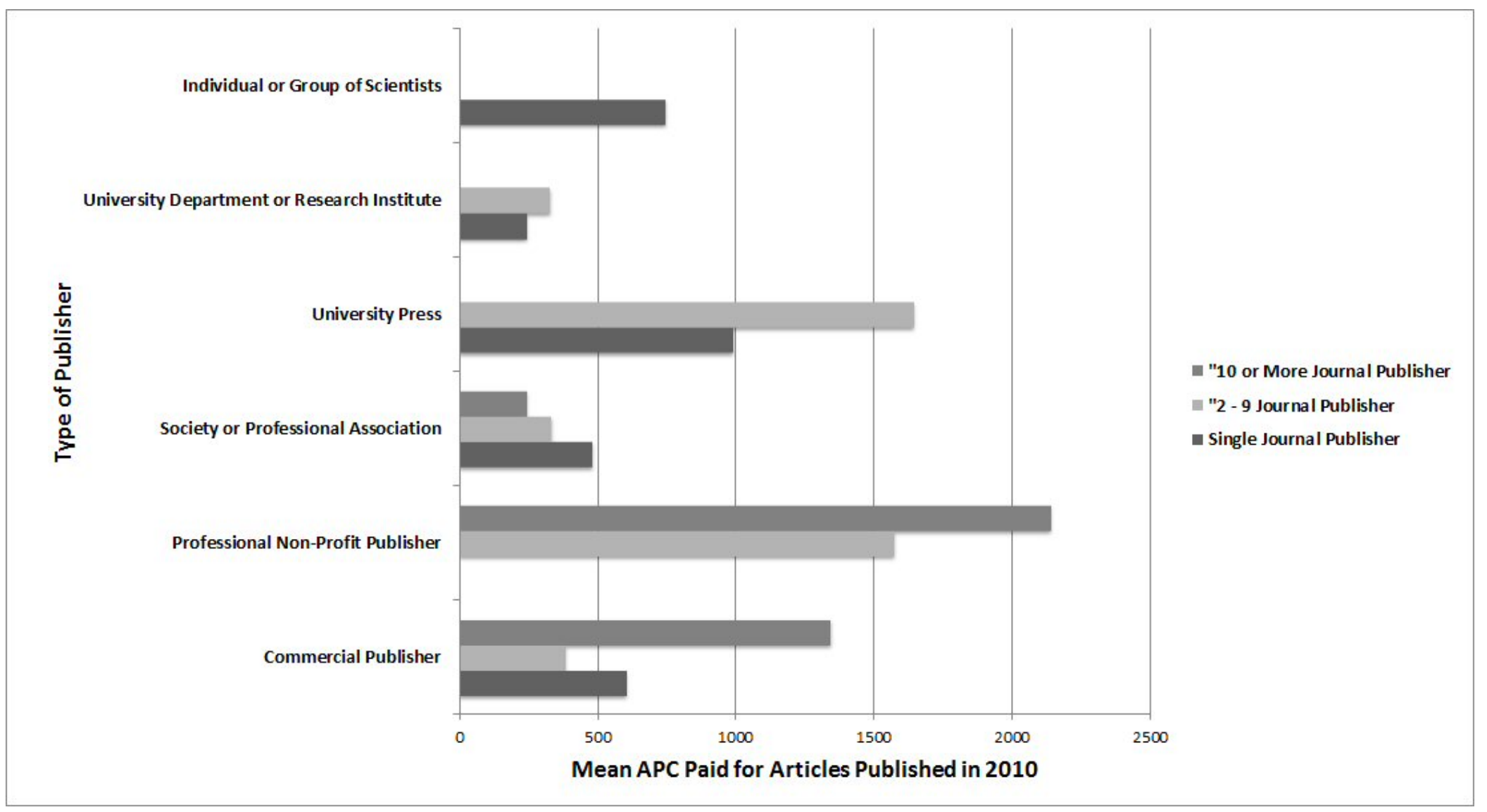

Figure 2 Breakdown of Articles Published in $\mathbf{2 0 1 0}$ by Type and Size of Publisher 


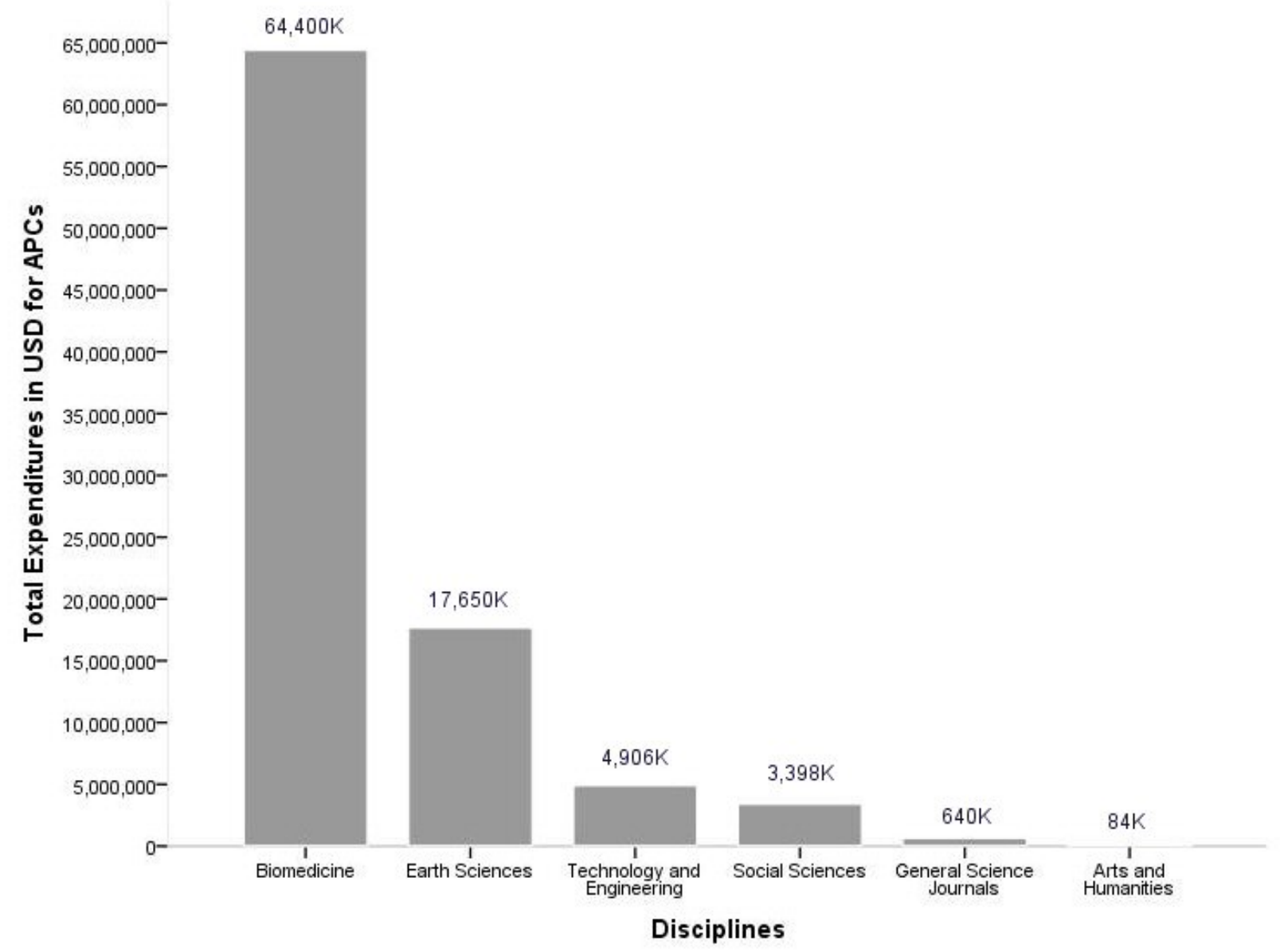

Figure 3: Total Expenditures for Article Processing Charge in 2010 by Discipline

Note: Numbers above bars are expenditures in USD rounded to the nearest $\$ 1,000$ 


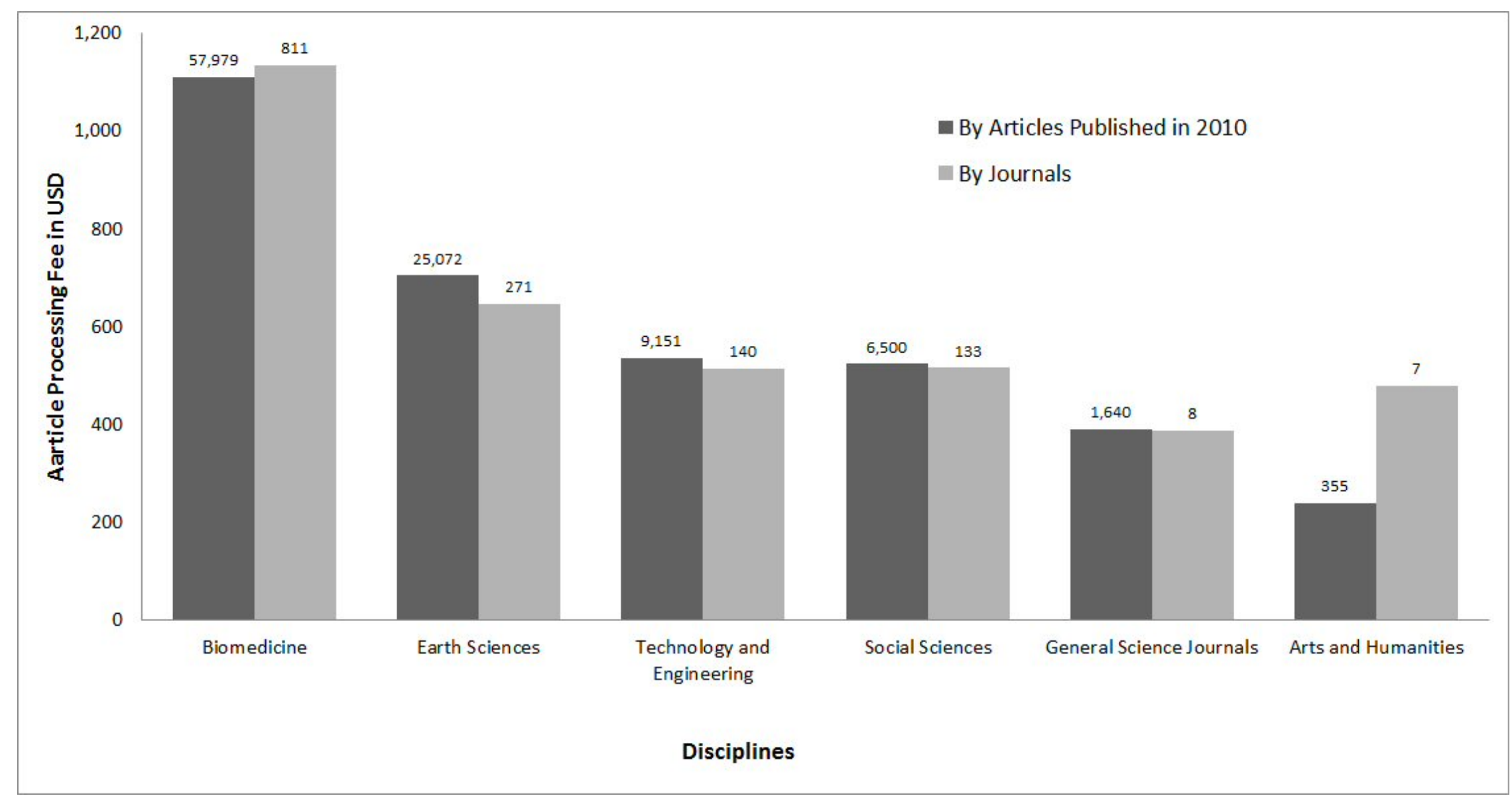

Figure 4: Average Article Processing Charge by Subject Matter Area

Note: Numbers above the bars are articles published in $2010 /$ Journals 


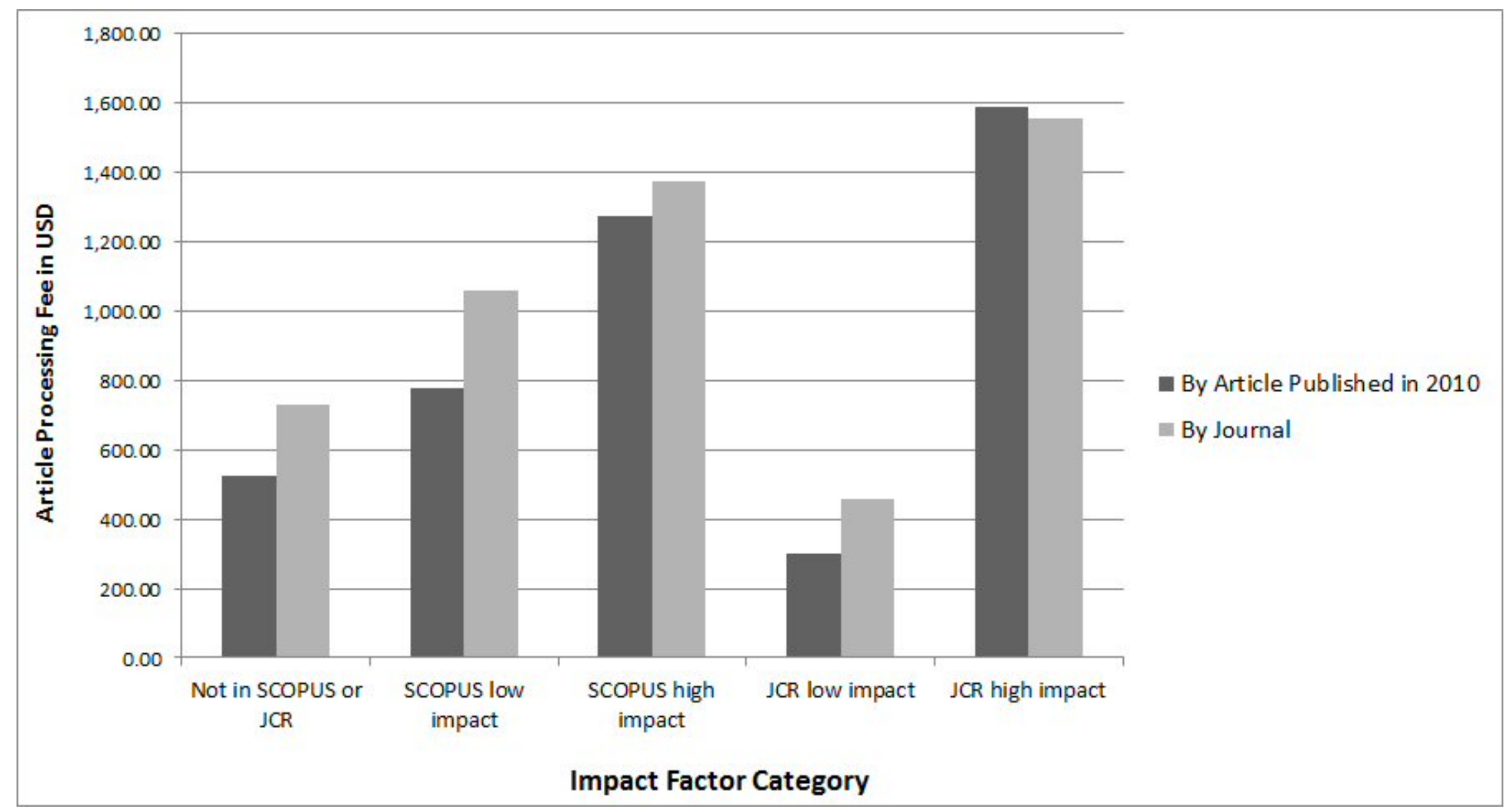

Figure 5: Average Article Processing Charge by Impact Factor Category 


\section{Listing of Publishers included in the Sample}

Publisher

Bentham Open
BioMed Central
Hindawi Publishing Corporation
Dove Medical Press
Libertas Academica
Scientific Research Publishing
Frontiers Research Foundation
MDPI AG
AIRCC*
Canadian Center of Science and Education
OMICS Publishing Group
PAGEPress Publications
Copernicus Publications
Springer
Co-Action Publishing
Maxwell Science Publication
Academic and Business Research Institute
Kamla-Raj Enterprises
Public Library of Science (PLoS)
Academic Journals
Internet Scientific Publications, LLC
OpenJournals Publishing
Academy Publisher
e-Century Publishing Corporation
AstonJournals
Karger Publishers
Macrothink Institute
21 publishers with 2-4 journals
64 publishers with 1 journal
Mat

\section{Country Journals}

Arab Emirates

United

Kingdom

Egypt

New Zealand

New Zealand

United States

Switzerland

Switzerland

India

Canada

United States

Italy

Germany

Germany

Sweden

Pakistan

United States

India

United States

Nigeria

United States

South Africa

Finland

United States

United States

Switzerland

United States
211

193

132

81

58

48

26

25

21

20

20

18

13

12

10

10

9

9

8

7

7

7

6

6

5

5

5

54

64

1090
Article Count

1941

16066

3943

2034

459

2279

1152

3957

624

1877

329

433

2089

1437

192

429

243

378

9065

3095

117

227

898

238

50

265

91

6586

15483

75977

Totals 


\section{Average APC in USD by Type of Publisher and Size of Journal Portfolio for Articles Published in 2010}

\begin{tabular}{|c|c|c|c|c|}
\hline & $\begin{array}{l}\text { Single } \\
\text { Journal }\end{array}$ & 2-9 Journals & $\geq 10$ Journals & Totals \\
\hline \multicolumn{5}{|l|}{ Type of Publisher } \\
\hline Commercial Publisher & $606 / 1,623$ & $384 / 11,452$ & 1,345 / 36,164 & $1,097 / 49,239$ \\
\hline $\begin{array}{l}\text { Professional Non-Profit } \\
\text { Publisher }\end{array}$ & & $1,574 / 9,243$ & $2,141 / 1,152$ & $1,635 / 10,395$ \\
\hline $\begin{array}{l}\text { Scientific Society or } \\
\text { Professional Association }\end{array}$ & $482 / 24,888$ & 335 / 89 & $255 / 2,501$ & $461 / 27,478$ \\
\hline University Press & 991 / 476 & $1,645 / 1,998$ & & $1,519 / 2,474$ \\
\hline $\begin{array}{l}\text { University, University } \\
\text { Department, Research } \\
\text { Institute }\end{array}$ & $245 / 9,231$ & $329 / 125$ & & $246 / 9,356$ \\
\hline $\begin{array}{l}\text { Individual Scientist or } \\
\text { Group of Scientists }\end{array}$ & 747 / 1,755 & & & 747 / 1,755 \\
\hline Totals & $488 / 37,973$ & 974 / 22,907 & $1,300 / 39,817$ & $904 / 100,697$ \\
\hline
\end{tabular}

Note: Table cells contain the "mean APC / number of articles."

\section{Average APC in USD by Type of Publisher and Size of Journal Portfolio for Journals}

$\begin{array}{lccc}\begin{array}{c}\text { Single } \\ \text { Journal }\end{array} & \text { 2-9 Journals } & \geq 10 \text { Journals } & \text { Totals } \\ 547 / 41 & 362 / 131 & 1,132 / 849 & \mathbf{1 , 0 1 0 / 1 , 0 2 1} \\ & 1,289 / 14 & 2,141 / 26 & 1,843 / 40 \\ 438 / 165 & 331 / 3 & 208 / 41 & 391 / 209 \\ 1,065 / 10 & 704 / 10 & & \mathbf{8 8 5} / 20 \\ 287 / 60 & 222 / 2 & & 284 / 62 \\ 1,058 / 18 & & & 1,058 / 18 \\ 482 / 294 & 462 / 160 & 1,120 / 916 & 906 / 1,370\end{array}$

Type of Publisher

Commercial Publisher

Professional Non-

Commercial Publisher

Scientific Society or

Professional Association

University Press

University, University

Department, Research Institute

Individual Scientist or Group of Scientists

Totals

$482 / 294$

$462 / 160$

$1,120 / 916$

Note: Table cells contain "mean APC / number of journals." 


\section{Median APC in USD by Type of Publisher and Size of Journal Portfolio for Articles Published in 2010}

\begin{tabular}{|c|c|c|c|c|}
\hline & $\begin{array}{l}\text { Single } \\
\text { Journal }\end{array}$ & 2-9 Journals & $\geq 10$ Journals & Totals \\
\hline \multicolumn{5}{|l|}{ Type of Publisher } \\
\hline Commercial Publisher & $358 / 1,623$ & $400 / 11,452$ & 1,610 / 36,164 & $1,000 / 49,239$ \\
\hline $\begin{array}{l}\text { Professional Non- } \\
\text { Commercial Publisher }\end{array}$ & & $1,350 / 9,243$ & $2,141 / 1,152$ & $1,350 / 10,395$ \\
\hline $\begin{array}{l}\text { Scientific Society or } \\
\text { Professional Association }\end{array}$ & $220 / 24,888$ & $302 / 89$ & $300 / 2,501$ & $258 / 27,478$ \\
\hline University Press & $1,110 / 476$ & $2770 / 1,998$ & & $1,110 / 2,474$ \\
\hline $\begin{array}{l}\text { University, University } \\
\text { Department, Research } \\
\text { Institute }\end{array}$ & 152 / 9,231 & $401 / 125$ & & $153 / 9,356$ \\
\hline $\begin{array}{l}\text { Individual Scientist or } \\
\text { Group of Scientists }\end{array}$ & $125 / 1,755$ & & & $125 / 1,755$ \\
\hline Totals & $152 / 37,973$ & $650 / 22,907$ & $1,610 / 39,817$ & $740 / 100,697$ \\
\hline
\end{tabular}

Note: Table cells contain the "median / number of articles."

\section{Median APC in USD by Type of Publisher and Size of Journal} Portfolio for Journals

$\begin{array}{lccc}\begin{array}{c}\text { Single } \\ \text { Journal }\end{array} & \text { 2-9 Journals } & \geq \text { 10 Journals } & \text { Totals } \\ 358 / 41 & 250 / 131 & 1,000 / 849 & \mathbf{8 0 0} / \mathbf{1 , 0 2 1} \\ & 928 / 14 & 2,141 / 26 & \mathbf{2 , 1 4 1 / 4 0} \\ 322 / 165 & 302 / 3 & 120 / 41 & \mathbf{3 0 0} / \mathbf{2 0 9} \\ 1,110 / 10 & 174 / 10 & & \mathbf{1 , 1 1 0 / 2 0} \\ 152 / 60 & 222 / 2 & & 152 / 62 \\ 1,057 / 18 & & & \mathbf{1 , 0 5 8 / 1 8} \\ \mathbf{3 2 2} / \mathbf{2 9 4} & 551 / \mathbf{1 6 0} & \mathbf{8 7 0} / \mathbf{9 1 6} & \mathbf{8 0 0} / \mathbf{1 , 3 7 0}\end{array}$

Type of Publisher

Commercial Publisher

Professional Non-

Commercial Publisher

Scientific Society or

Professional Association

University Press

University, University

Department, Research Institute

Individual Scientist or Group of Scientists

Totals

$551 / 160$

$870 / 916$

$800 / 1,370$

Note: Table cells contain "median / number of journals." 